\title{
Allosteric AKT Inhibitors Target Synthetic Lethal Vulnerabilities in E-Cadherin-Deficient Cells
}

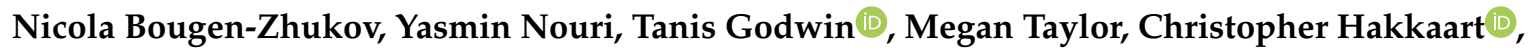 \\ Andrew Single, Tom Brew, Elizabeth Permina, Augustine Chen, Michael A. Black and \\ Parry Guilford * (D) \\ Cancer Genetics Laboratory, Centre for Translational Cancer Research (Te Aho Matatū), Department of \\ Biochemistry, University of Otago, Dunedin 9016, New Zealand; nicola.bougen-zhukov@otago.ac.nz (N.B.-Z.); \\ yasminnouri1994@gmail.com (Y.N.); tanis.godwin@otago.ac.nz (T.G.); tayme744@student.otago.ac.nz (M.T.); \\ christopher.hakkaart@otago.ac.nz (C.H.); andrew.single@med.lu.se (A.S.); tom.p.brew@gmail.com (T.B.); \\ elizabeth.permina@otago.ac.nz (E.P.); augustine.chen@otago.ac.nz (A.C.); mik.black@otago.ac.nz (M.A.B.) \\ * Correspondence: parry.guilford@otago.ac.nz; Tel.: +64-3-479-7673
}

Received: 29 July 2019; Accepted: 10 September 2019; Published: 13 September 2019

check for updates

\begin{abstract}
The CDH1 gene, encoding the cell adhesion protein E-cadherin, is one of the most frequently mutated genes in gastric cancer and inactivating germline $C D H 1$ mutations are responsible for hereditary diffuse gastric cancer syndrome (HDGC). Using cell viability assays, we identified that breast (MCF10A) and gastric (NCI-N87) cells lacking CDH1 expression are more sensitive to allosteric AKT inhibitors than their CDH1-expressing isogenic counterparts. Apoptosis priming and total apoptosis assays in the isogenic MCF10A cells confirmed the enhanced sensitivity of E-cadherin-null cells to the AKT inhibitors. In addition, two of these inhibitors, ARQ-092 and MK2206, preferentially targeted mouse-derived gastric $C d h 1^{-/-}$organoids for growth arrest. AKT protein expression and activation (as measured by phosphorylation of serine 473) were differentially regulated in E-cadherin-null MCF10A and NCI-N87 cells, with downregulation in the normal breast cells, but upregulation in the gastric cancer cells. Bioinformatic analysis of the TCGA STAD dataset revealed that $A K T 3$, but not $A K T 1$ or $A K T 2$, is upregulated in the majority of E-cadherin-deficient gastric cancers. In conclusion, allosteric AKT inhibitors represent a promising class of drugs for chemoprevention and chemotherapy of cancers with E-cadherin loss.
\end{abstract}

Keywords: E-cadherin; AKT; diffuse gastric cancer; synthetic lethality; chemoprevention

\section{Introduction}

CDH1, encoding the cell-cell adhesion protein E-cadherin [1], is a tumour suppressor gene that is frequently mutated in sporadic diffuse-type gastric cancer (DGC), lobular breast cancer in situ (LCIS), and invasive lobular breast cancer (LBC) [2]. In addition, inactivating germline mutations in CDH1 are causative of the highly penetrant, inherited cancer syndrome hereditary diffuse gastric cancer (HDGC) [3]. HDGC is characterised by multifocal stage T1a gastric signet ring cell carcinomas in over $95 \%$ of mutation carriers from a young age and a 70\% lifetime risk of advanced DGC [4]. Female CDH1 mutation carriers also have a 40\% risk of developing LBC [5]. Currently, prophylactic gastrectomy is the recommended option for gastric cancer risk reduction in mutation carriers, despite the high associated morbidity [6].

The frequency of CDH1 loss in sporadic and familial DGC, LCIS, and LBC suggests that targeting E-cadherin-deficiency in these cancers may provide an effective method for the chemoprevention of HDGC and new treatments for the sporadic disease. This is of particular importance for DGC, which shows a poorer response to many of the currently used chemotherapeutics than the more 
common intestinal form of gastric cancer (IGC) [7]. Because CDH1 is a tumour suppressor gene, we have been taking a synthetic lethal approach to identify druggable vulnerabilities created by loss of E-cadherin [8,9]. Synthetic lethality is classically defined as a genetic interaction in which a combination of mutations in two or more genes leads to cell death [10]. In a therapeutic setting, the term can refer to the use of targeted drugs to cause cell death preferentially in tumours carrying specific genetic alterations. By carrying out RNAi and known drug screens on isogenic breast and gastric cell lines with and without E-cadherin, we have identified multiple druggable vulnerabilities in E-cadherin-deficient cells which may be exploited for both the chemoprevention of HDGC and the treatment of sporadic DGC, LCIS, and LBC [8,9]. The screen data has also led to a model in which the principal vulnerability in E-cadherin-deficient cells is disruption of plasma membrane organisation and the associated cytoskeleton, leading to abnormal cell survival signalling, particularly through PI3K/AKT [9]. This model is supported by demonstration that E-cadherin-mediated cell contacts lead to direct signalling through the PI3K/AKT pathway [11], as well as indirect activation of AKT signalling after ligand independent activation of growth factor receptors such as EGFR [12]. Furthermore, proteomic analysis has shown that the AKT and EGFR pathways are upregulated in CDH1-mutated gastric tumours [13].

Here, we have searched for inhibitors of PI3K/AKT signalling that show the greatest differential activity against E-cadherin-deficient cells, and tested their synthetic lethal (SL) effect using apoptosis assays and isogenic mouse-derived organoids. Our data show, for the first time, that allosteric AKT inhibitors preferentially promote apoptosis in CDH1-deficient cells. We postulate that this susceptibility to allosteric AKT inhibition could be a novel chemopreventative and chemotherapeutic strategy for CDH1 germline mutation carriers and E-cadherin-negative sporadic cancers, respectively.

\section{Results}

\subsection{Allosteric AKT Inhibitors Preferentially Target Breast Cells Lacking CDH1}

A previous drug screen conducted in our laboratory identified the ATP-competitive AKT inhibitor AZD5363 as a drug which could preferentially slow the growth of MCF10A (non-malignant breast) and NCI-N87 (gastric cancer) cells that are deficient in E-cadherin [9]. For this assay, we utilised a previously characterised pair of isogenic cell lines: MCF10A-WT (containing wild-type (WT) CDH1) and MCF10A-CDH1 ${ }^{-/-}$(containing a deletion in the CDH1 locus) (Supplementary Figure S1A) [14]. This cell line was employed to model the effect of $C D H 1$ deletion on normal (breast) cell response to chemopreventive strategies. Initially, we tested another ATP-competitive AKT inhibitor, Ipatasertib [15]; however, no difference was seen between $\mathrm{WT}$ and $\mathrm{CDH1}^{-/-}$cell survival after this treatment (Figure 1A). Given the abundance of AKT inhibitors in development for cancer treatment [16], we expanded our screen to include allosteric AKT inhibitors, a newer class of inhibitors that are postulated to have enhanced specificity, reduced side effects, and lower toxicity than other classes of AKT inhibitors [17]. The allosteric AKT inhibitors used in this study, ARQ-092 [18], MK2206 [19], perifosine [20], SC66 [21], and PHT-427 [22], can bind directly to AKT to inhibit its activation and downstream signalling. Importantly, allosteric AKT inhibitors (unlike the ATP-competitive class) do not cause hyperphosphorylation of AKT as a treatment-dependent compensation of signalling [23].

After $48 \mathrm{~h}$ treatment with a range of (drug-dependent) concentrations, the MCF10A-CDH1 ${ }^{-/-}$ cells exhibited a greater sensitivity to the four allosteric AKT inhibitors ARQ-092, MK2206, perifosine, and SC66 (Figure 1B-E), confirming a vulnerability of CDH1-deficient cells to inhibition of AKT. No significant difference was seen in cells treated with PHT-427, a dual AKT/PDK1 allosteric inhibitor [24] (Figure 1F). 

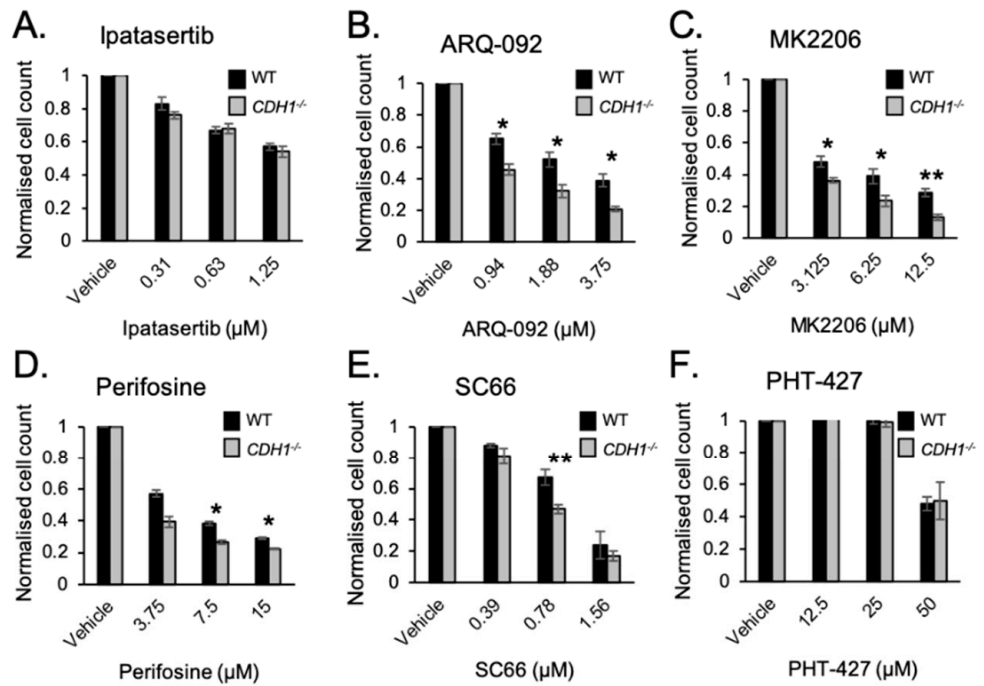

G.
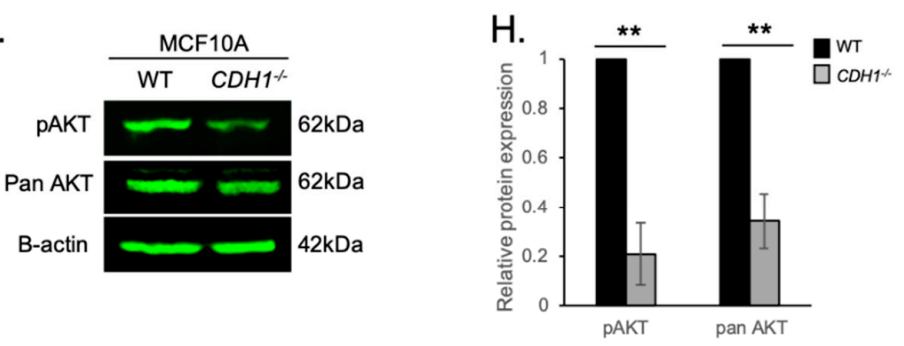

I.
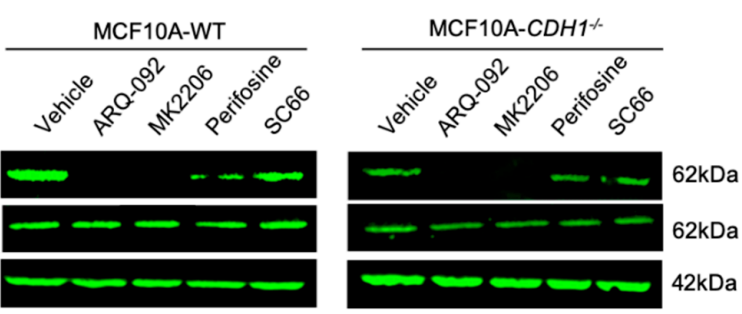

Figure 1. Non-malignant breast cells lacking E-cadherin exhibit a higher sensitivity to the allosteric AKT inhibitors ARQ-092, MK2206, perifosine, and SC66. (A-F) Normalised MCF10A-WT and CDH1 ${ }^{-/-}$ cell counts $48 \mathrm{~h}$ after treatment with serial dilutions of Ipatasertib (A), ARQ-092 (B), MK2206 (C), Perifosine (D), SC66 (E), and PHT-427 (F). Wild-type, black bars; $\mathrm{CDH1}^{-/}$, grey bars. Six fields per well at $4 \times$ magnification were captured using the Cytation 5 imager (Biotek). Nuclei were counted using Gen5 (Biotek) and normalised to the vehicle control for each cell line. (G) Western blots of pAKT-Ser473 and pan-AKT levels in untreated MCF10A-WT and $\mathrm{CDH1} 1^{-/}$cells. (H) Relative expression of pAKT and pan-AKT in MCF10A-WT and $\mathrm{CDH1}^{-/-}$cells. (I) Western blots of pAKT-Ser473 and pan-AKT levels in MCF10A-WT and $\mathrm{CDH1}^{-/-}$cells after $4 \mathrm{~h}$ of DMSO or allosteric AKT inhibitor treatments; vehicle (0.1\% DMSO), ARQ092 $(2 \mu \mathrm{M})$, MK2206 $(6.25 \mu \mathrm{M})$, perifosine $(7.5 \mu \mathrm{M})$, and SC66 $(0.78 \mu \mathrm{M})$. (For all graphs, error bars $=\mathrm{SEM} ; \mathrm{ns}=p>0.05,{ }^{*}=p<0.05,{ }^{* *}=p<0.01, n \geq 3$ independent biological replicates; unpaired two-sided $t$-test.)

We next examined both the basal and post-drug treatment protein levels of phosphorylated AKT (phospho-Ser473) and total AKT in the isogenic MCF10A cell lines. Interestingly, basal levels of both p-AKT (Ser473) and pan-AKT were significantly lower in MCF10A-CDH1 ${ }^{-/-}$cells compared with WT cells (Figure 1G). It was more difficult to detect phospho-473 in MCF10A-CDH ${ }^{-/}$cells as they expressed $\sim 20 \%$ less of the amount in MCF10A-WT cells (Figure $1 \mathrm{H}$ ). Pan-AKT protein levels in $\mathrm{CDH1}^{-/-}$cells were $>60 \%$ less than WT (Figure $1 \mathrm{H}$ ). pAKT and pan-AKT protein levels were also measured in the isogenic cell lines after treatments with the four allosteric inhibitors identified as 
synthetic lethal candidates in Figure 1B-E. After $4 \mathrm{~h}$ treatment with ARQ-092 (2 $\mu$ M) and MK2206 $(6.25 \mu \mathrm{M})$, phosphorylation of AKT on serine 473 was completely inhibited in both cell lines. Treatment with perifosine $(7.5 \mu \mathrm{M})$ slightly reduced pAKT in both cell lines. SC66 $(0.78 \mu \mathrm{M})$ treatment appeared to have a limited effect on pAKT in either cell line after $4 \mathrm{~h}$ treatment. SC66 has been demonstrated to enhance ubiquitinylation and subsequent proteosomal degradation of $\mathrm{AKT}$, thus providing an alternative method for growth inhibition effects seen in these cells [21]. None of the drugs tested had a detectable effect on pan-AKT expression in either cell line.

\subsection{CDH1-Negative Breast Cells Have Enhanced Apoptotic Priming and Apoptosis Induction after Allosteric AKT Inhibitor Treatment}

The results of our nuclei enumeration assay (Figure 1) indicate that non-malignant breast $\mathrm{CDH} 1^{-/-}$ cells are more sensitive to the effects of AKT inhibition. However, this assay simply measures endpoint nuclei number and does not clarify if the reduced number of $\mathrm{CDH1}^{-/-}$cells is due to a cytostatic or cytotoxic effect of these drugs. The allosteric AKT inhibitors utilised in this study, such as MK2206, have been shown to induce both apoptosis [25] and/or autophagy [26] in different cell lines.

To clarify the potential mechanism by which these small molecule inhibitors preferentially affect $\mathrm{CDH}^{-/-}$cells, we measured the degree of readiness for apoptosis, hereafter referred to as "apoptotic priming", in our cell lines after 16-20 h of drug treatment. Apoptotic priming was measured by an assay described in Ryan et al. [27], whereby DMSO or drug-treated cells are stained with JC-1 dye and exposed to pro-apoptotic BH3 peptides, such as BIM. If cells are primed for apoptosis, then the exposure to $\mathrm{BH} 3$ peptides will lead to mitochondrial outer membrane depolarisation (MOMP) and the JC-1 dye will shift from red aggregates within the mitochondria to green monomers. This decrease in red fluorescence can be used to determine the extent of depolarisation [28]. We observed that all of our AKT inhibitors primed both MCF10A-WT and $C D H 1^{-1-}$ cells for apoptosis. However, the extent of depolarisation was significantly higher in the $\mathrm{CDH} 1^{-/-}$cells for all of the inhibitors tested except for the PI3K inhibitor PI103 (Figure 2A). Under the conditions tested, all of the AKT inhibitors (AZD5363, ARQ-092, MK2206, perifosine, and SC66) preferentially primed CDH1 ${ }^{-/}$cells with 20-40\% more mitochondrial membrane depolarisation than WT cells (Figure 2A and Supplementary Figure S2A).

To test if the apoptotic priming translated into differences in the induction of apoptosis, we measured apoptosis by flow cytometry analysis of Annexin-V-FITC/Propidium iodide stained cells (Figure 2B) after $72 \mathrm{~h}$ treatment. The results of this assay confirmed that the detection of apoptotic priming was generally a good indicator of future apoptosis, with consistent priming and FACS results for all of the allosteric AKT inhibitors tested (Figure 2B). However, despite the ATP-competitive AKT inhibitor AZD5363 $(10 \mu \mathrm{M})$ leading to almost 80\% depolarisation in our CDH1 ${ }^{-/-}$cells $(\sim 30 \%$ more than WT) (Figure 2A and Supplementary Figure S2A), the levels of apoptosis detected in cells treated with this drug for $72 \mathrm{~h}$ were not significantly higher than DMSO-treated controls (Figure 2B and Supplementary Figure S2B). However, the allosteric AKT inhibitors all exhibited significantly higher apoptosis induction in MCF10A-CDH1-/- cells compared with WT cells (Figure 2E and Supplementary Figure S2C). Out of the AKT inhibitors, MK2206 (6.25 $\mu \mathrm{M})$ treatment induced the highest level of apoptosis in the MCF10A-CDH1 ${ }^{-/-}$cells (20.2\%). Interestingly, despite there being no significant difference in apoptotic priming detected between WT and CDH1 ${ }^{-/-}$cells after $20 \mathrm{~h}$ of PI103 $(1 \mu \mathrm{M})$ treatment (Figure 2A), at $72 \mathrm{~h}$ there was a significantly different level of apoptosis induced: WT 7\% vs. $\mathrm{CDH} 1^{-/-} 22.2 \%{ }^{* *}$, a 3.17-fold difference (Figure 2B and Supplementary Figure S2B,C). Potentially, despite the initiation of priming in MCF10A-WT cells after PI103 treatment, these cells may be more adept than MCF10A-CDH1 ${ }^{-/-}$cells in resisting the induction of apoptosis. 
A. $\quad$ wT

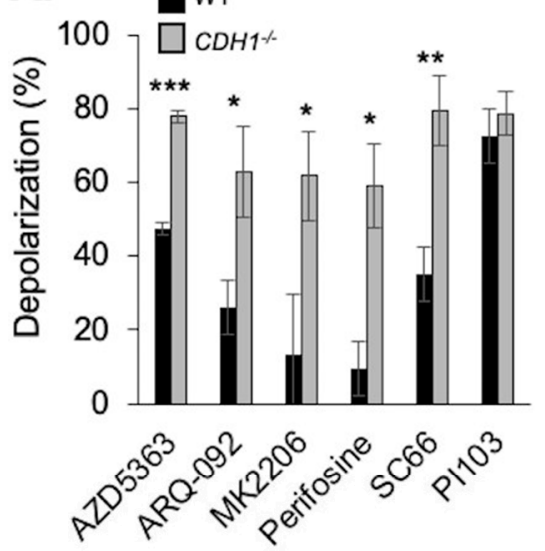

B.

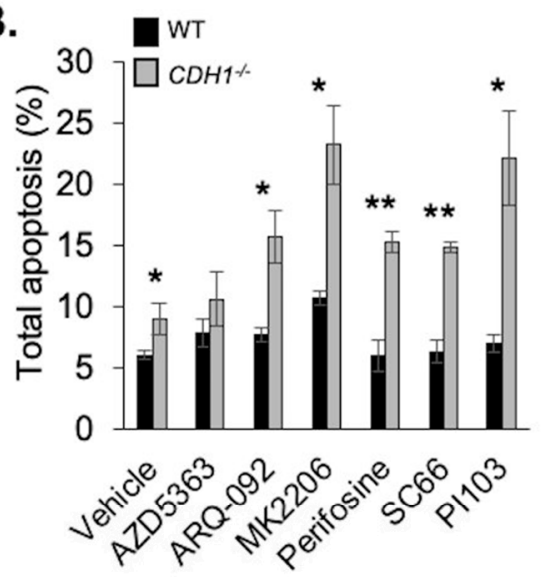

C.

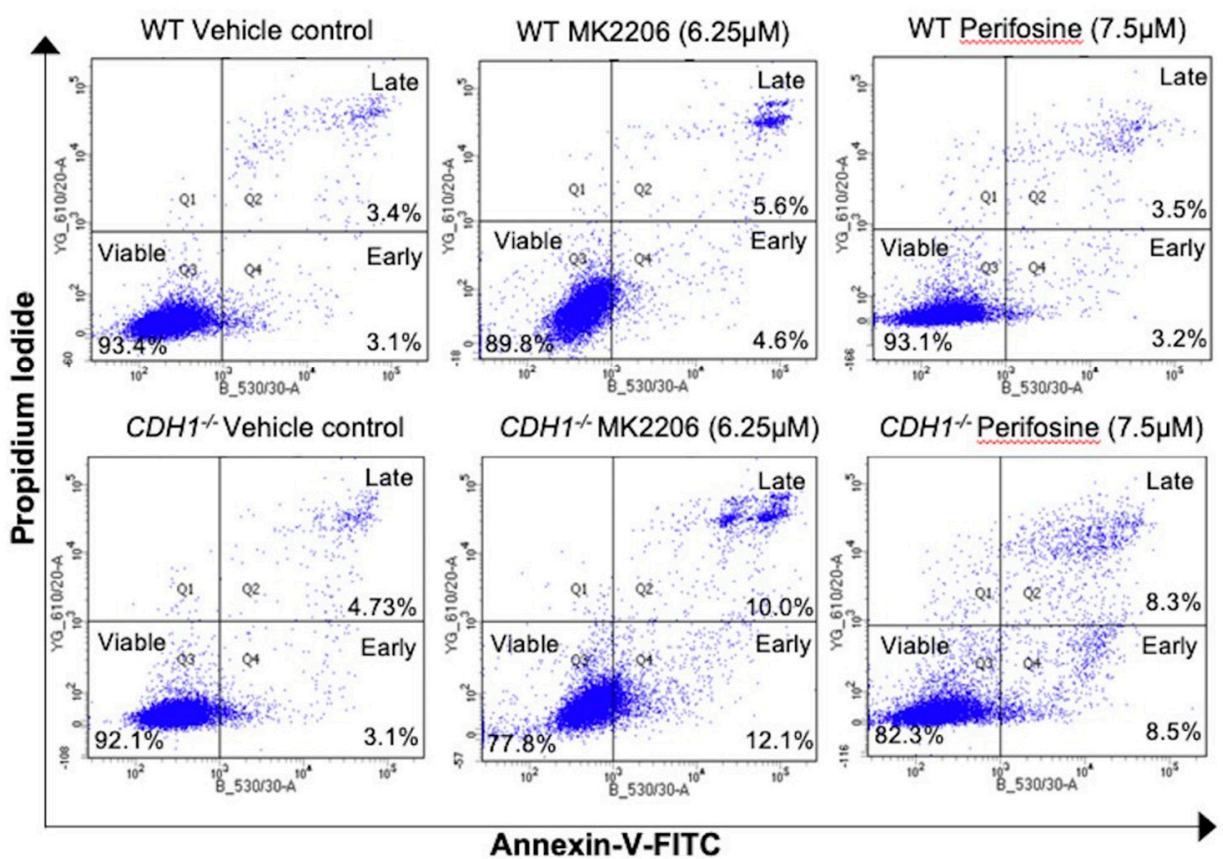

Figure 2. Inhibition of AKT preferentially primes $C D H 1$-null cells for apoptosis. (A) Mitochondrial membrane depolarisation in MCF10A-WT and $\mathrm{CDH1}^{-/-}$cells after $16-20 \mathrm{~h}$ treatment with AKT inhibitors. (B) Total apoptosis (Annexin-V-FITC and propidium iodide positive cells) detected by flow cytometry after $72 \mathrm{~h}$ drug treatment. (C) Representative histograms of MCF10A-WT and CDH1 ${ }^{-/-}$ cells stained with Annexin-V-FITC and propidium iodide and analysed on BD Fortessa flow cytometer. (For all graphs, error bars $=$ SEM; ns $=p>0.05,{ }^{*}=p<0.05,{ }^{* *}=p<0.01,{ }^{* *}=p<0.001 ; n \geq 3$ independent biological replicates; unpaired two-sided $t$-test.)

\subsection{CDH1-Negative Gastric Cells Are More Sensitive to the Allosteric AKT Inhibitors ARQ-092 and MK2206}

To determine if the synthetic lethal (SL) relationship identified between CDH1 and allosteric inhibition of AKT was present in cancer cell lines, we tested the allosteric AKT inhibitors in an isogenic cell line pair derived from NCI-N87 gastric cancer cells: NCI-N87-WT and NCI-N87-CDH ${ }^{-/-}$ (Supplementary Figure S1B). Prior to drug testing, we measured the basal expression of pAKT (Serine 473) and total AKT (Figure 3A). Surprisingly, unlike the MCF10A isogenic cell lines, the NCI-N87 cells lacking $C D H 1$ had 1.7-fold higher basal levels of pAKT than NCI-N87-WT cells (Figure 3B). Pan-AKT levels were also increased (1.75-fold) in the NCI-N87-CDH1 ${ }^{-1-}$ cells compared with WT (Figure 3B). These cells were generally more resistant than the MCF10A cells to the AKT inhibitors, 
with increased $\mathrm{IC}_{50}$ values for all of the drugs tested (Figure 3C-F). For example, the ARQ-092 $\mathrm{IC}_{50}$ in MCF10A-WT cells was $\sim 1.88 \mu \mathrm{M}$ (Figure 1B) vs. $\sim 25 \mu \mathrm{M}$ in NCI-N87-WT cells (Figure 3C). Importantly, we observed a strong SL effect after treatment with ARQ-092 and MK2206 in the NCI-N87-CDH1 ${ }^{-1}$ cell line (Figure 3C,D); however, no such effect was seen after perifosine or SC66 treatment (Figure 3E,F). Since the SL effect of ARQ-092 and MK2206 was consistent across two cell lines from different tissues (mammary vs. gastric) and of different disease states (normal vs. cancer), we decided to take these drugs forward into our gastric organoid model.
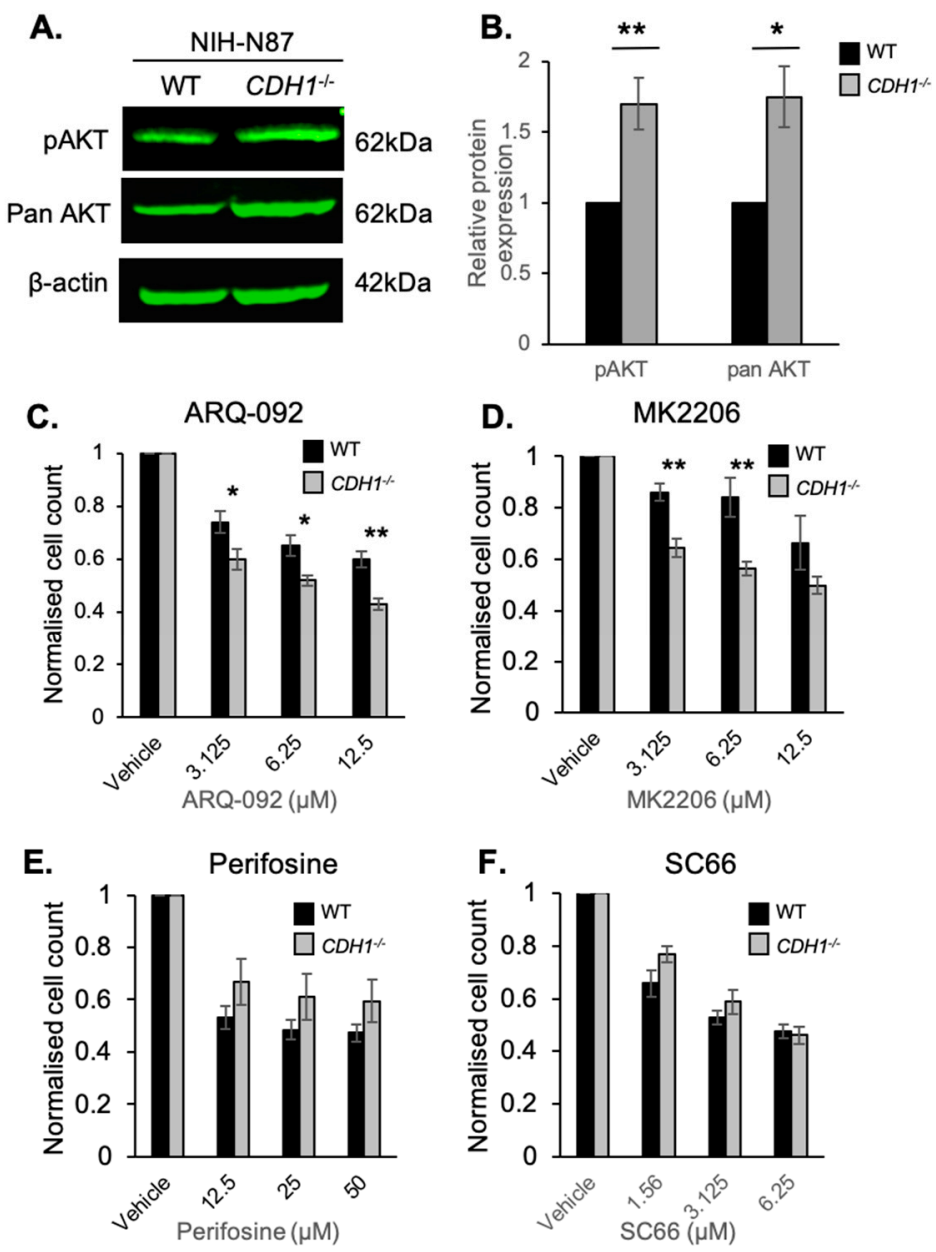

Figure 3. Gastric cancer cells lacking E-cadherin have enhanced sensitivity to the allosteric AKT inhibitors ARQ092 and MK2206. (A) Western blots of pAKT-Ser473, pan-AKT, and $\beta$-actin in NCI-N87-WT and $\mathrm{CDH1}^{-/-}$cells. (B) Relative expression of pAKT and pan-AKT in NCI-N87-WT and $\mathrm{CDH} 1^{-/-}$cells. (C-F) Normalised NCI-N87-WT and $\mathrm{CDH1}^{-/-}$cell counts $48 \mathrm{~h}$ after treatment with serial dilutions of ARQ-092 (C), MK2206 (D), perifosine (E), and SC66 (F). Wild-type, black bars; $\mathrm{CDH}^{-/-}$, grey bars. Six fields per well at $4 \times$ magnification were captured using the Cytation 5 imager (Biotek). Nuclei were counted using Gen5 (Biotek, Winooski, Vermont) and normalised to the vehicle control for each cell line. (For all graphs, error bars $=\mathrm{SEM}$; ns $=p>0.05,{ }^{*}=p<0.05,{ }^{* *}=p<0.01$, $n \geq 3$ independent biological replicates; unpaired two-sided $t$-test.)

\subsection{Allosteric AKT Inhibitors Preferentially Slow the Growth of Cdh1-Deleted Organoids}

To address the inherent limitations of two-dimensional (2D) cell culture models, such as cell population homogeneity and lack of three-dimensional (3D) structures, we next tested our top candidate drugs (ARQ-092 and MK2206) in mouse-derived gastric organoids. Organoids are 3D structures comprised of both differentiated and stem cells, which in part recapitulate the organisation and function of target organs. Propagated in vitro, these spherical cell cultures have the delicate organisation of the 
in vivo gastric gland, albeit on a simpler scale. Our organoids contained a $C D 44-C r e / C d h 1^{(\mathrm{f} / \mathrm{fl})} / \mathrm{TdTomato}$ construct, which allows for the inducible cellular knockout of $C d h 1$ upon treatment with endoxifen, resulting in organoids containing a mixture of $C d h 1$-null and positive cells, hereafter referred to as Cdh1-deleted organoids. This mixture has similarities to the stomachs of germline CDH1 mutation carriers, whereby discrete regions of E-cadherin-negative gastric cells result in signet ring cell carcinoma formation in a greater milieu of E-cadherin-positive cells. WT organoids displayed uniform expression of E-cadherin (Supplementary Figure S3). We confirmed the percentage of organoid cells with deleted Cdh1 by staining organoids with an antibody specific for E-cadherin. After induction, organoids had an average of $73 \% \mathrm{Cdh1}$ homozygous deletion per organoid (Supplementary Figure S4).

The DMSO-treated wild-type (WT) and Cdh1-deleted organoids displayed normal growth and no signs of death (Figure 4A,D). They increased in size significantly between day 2 and day 6 and, by day 6, showed no signs of disintegration, flattening, or substantial darkening. After $96 \mathrm{~h}$ treatment with $5 \mu \mathrm{M}$ ARQ-092, the WT organoids displayed relatively normal growth, although some showed darkening on both days 2 and 6 (Figure 4A). In contrast, Cdh1-deleted organoids that were exposed to ARQ-092 exhibited distinct death phenotypes (Figure 4D). By day 6, these organoids had lost their transparency, and were instead comprised of darkened, grainy tissue. This darkening indicated dying cells, and the grainy texture along with the disrupted borders suggested that the organoids were beginning to lose their structure and break down.

We also tested MK2206 efficacy in our organoid model. WT organoids that had been exposed to MK2206 $(6.25 \mu \mathrm{M})$, showed no obvious signs of death by day $6,96 \mathrm{~h}$ after initial drug exposure (Figure 4A). However, the MK2206-treated Cdh1-deleted organoids showed a marked decrease in growth rate and general health of the organoids (Figure 4D).

Change in organoid area was used as the primary quantitative measure of drug effectiveness. To measure this, the total area of each organoid was calculated on day 2 and day 6 , and the difference between the two calculated as a percentage change. By using percentage change, we were able to account for the relatively high levels of variation in growth rate and starting size of the organoids. These values (from all three replicates) were then plotted on a line graph, where each line represents one organoid (Figure 4B,C,E).

Both WT and Cdh1-deleted organoids treated with DMSO displayed normal growth and increased at comparable rates (Figure 4B). However, both the WT and Cdh1-deleted organoids grew at a significantly reduced rate after exposure to ARQ-092 (Figure 4C). Notably, there were a large number of $C d h 1^{-/-}$-deleted organoids displaying less than a 50\% total increase in size after ARQ-092 treatment. The average percent change in area across all organoids was calculated and plotted on a bar graph (Figure 4F). Over $96 \mathrm{~h}$ of treatment, WT organoids exposed to ARQ-092 had on average an 126\% increase in size, whereas Cdh1-deleted organoids showed a $45 \%$ average increase in size $(p=0.012)$.

The WT organoids exposed to MK2206 grew at a slightly reduced rate compared to DMSO-treated controls; however, the Cdh1-deleted organoids exposed to MK2206 showed a striking reduction in growth rate (Figure 4F). Over $96 \mathrm{~h}$ of treatment, WT organoids exposed to MK2206 had on average an $185 \%$ increase in size, whereas Cdh1 knock-down organoids showed only a $52 \%$ increase in size $(p=0.0005)$.

In order to account for the (non-significant) difference between the growth rates of WT and Cdh1-deleted organoids treated with DMSO, we normalised organoid change in area after drugs relative to DMSO (Figure 4G). After ARQ-092 treatment, WT organoids were on average 0.43-fold the size of DMSO controls, whereas Cdh1-deleted organoids were 0.19 -fold the size. However, due to relatively high variation, this result was not significant $(p=0.1)$. After MK2206 treatment, WT organoids were 0.6 -fold the size of DMSO controls, whereas C $d h 1$-deleted organoids were 0.23 -fold the size $(p=0.005)$. Therefore, allosteric inhibition of AKT demonstrates a significant synthetic lethal effect in our Cdh1-deleted organoids. 
A.

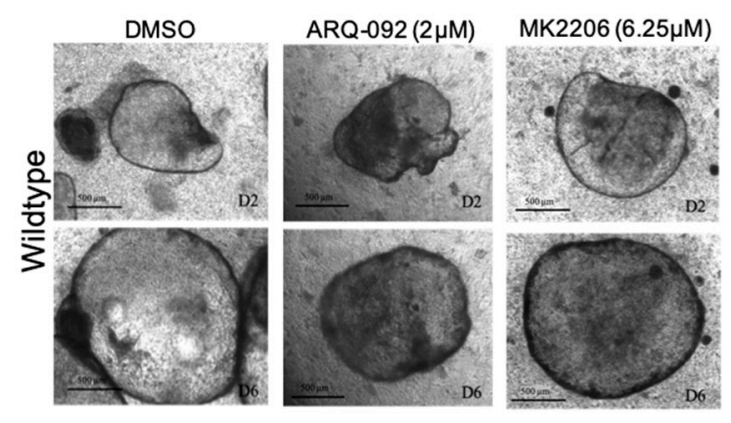

D.

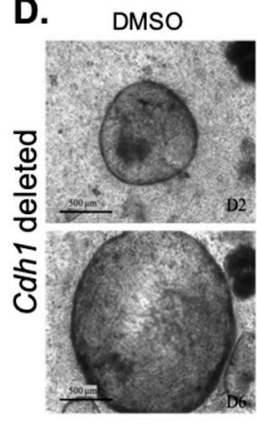

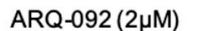
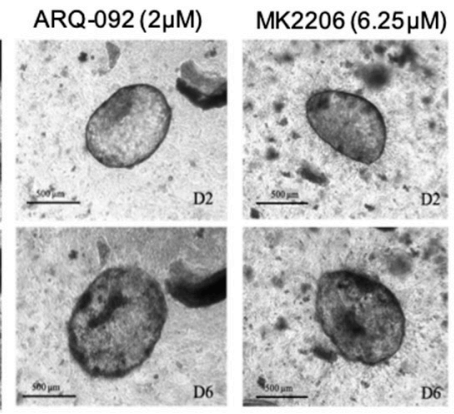

F.

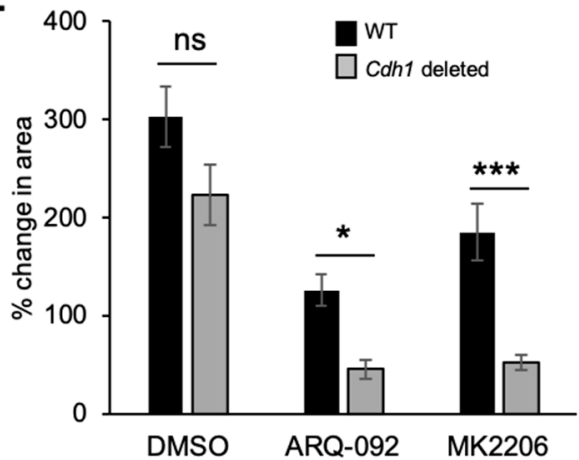

B.

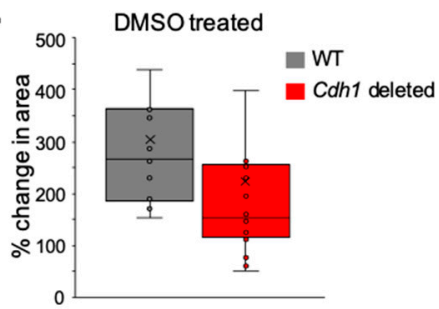

C.

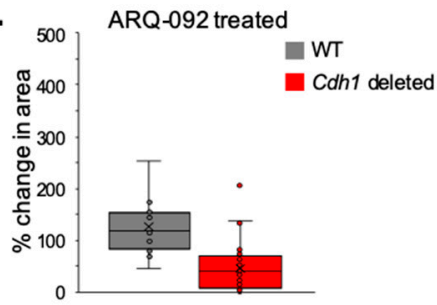

E.

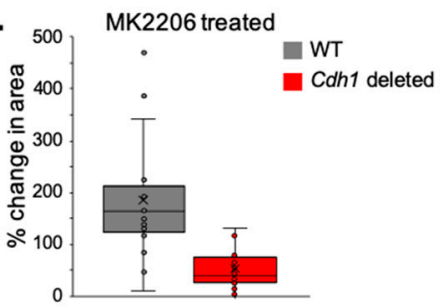

G.

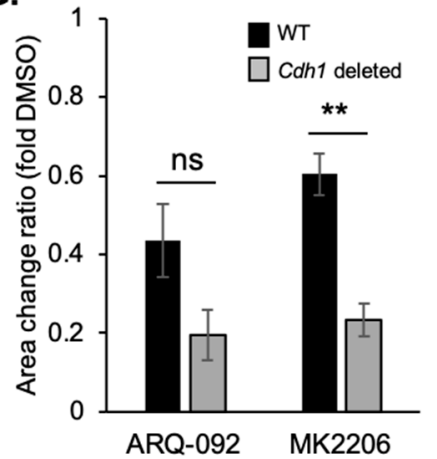

Figure 4. Mouse-derived gastric organoids containing Cdh1-null cells are more sensitive to the growth-inhibiting effects of allosteric AKT inhibitors. (A) Representative photos of wild-type (WT) organoids exposed to DMSO, ARQ-092, or MK2206 on day 2 (top panel) and day 6 (lower panel) of growth. (B,C) Box and whisker plots of \% change of area of individual organoids treated with DMSO (B) or ARQ-092 (C). (D) Representative photos of organoids containing Cdh1-null cells exposed to DMSO, ARQ-092, or MK2206 on day 2 and day 6 of growth. (E) Box and whisker plots of $\%$ change of area of individual organoids treated with MK2206. (F) Bar graph showing average \% change in area of organoids exposed to DMSO, ARQ-092, or MK2206 for $96 \mathrm{~h}$. (G) Bar graph showing the change in area of drug-treated organoids normalised to DMSO-treated organoids. (For all graphs, error bars = SEM; ns: $p>0.05, *: p<0.05,{ }^{* *}: p<0.01, * * *: p<0.001 ; n=3$ independent biological replicates; unpaired two-sided $t$-test.)

2.5. E-cadherin Expression Affects AKT Isoforms Differently in Breast and Gastric Cells (or in Normal and Cancer Cells)

To explore the relationship between $A K T$ isoform and $C D H 1$ expression in gastric cancer, we performed an analysis of gene expression data from a stomach cancer database containing information 
from 415 tumours (TCGA, STAD cohort) (Figure 5A). In these gastric tumour samples, there was a non-significant correlation between $A K T 1$ and $C D H 1$ expression (correlation $0.081, p=0.1$ ). Conversely, $A K T 3$ expression was significantly negatively correlated with $C D H 1$ expression (correlation -0.439 , $p$-value $\left.<2.2 \times 10^{-16}\right)$. There was no correlation between AKT2 and CDH1 expression in these tumour samples.

To further investigate the relationship between the loss of $C D H 1$ on AKT isoforms 1 and 3 in breast and gastric cancer cells, we measured the isoform protein expression in our cells. Both AKT1 and AKT3 protein levels were significantly decreased in MCF10A-CDH1 ${ }^{-/}$cells compared with WT cells (0.81- and 0.41-fold expression, respectively) (Figure 5B,C). In contrast, expression of the AKT1 and AKT3 isoforms were significantly increased in NCI-N87-CDH1 ${ }^{-/}$cells compared with NCI-N87-WT cells (1.52- and 2.09-fold, respectively) (Figure 5D,E). In general, increases in AKT expression are associated with enhanced cell survival; however, in certain circumstances, such as was seen in a model of ischaemia/reperfusion injury [29], AKT may induce apoptosis via feedback inhibition of PI3K.

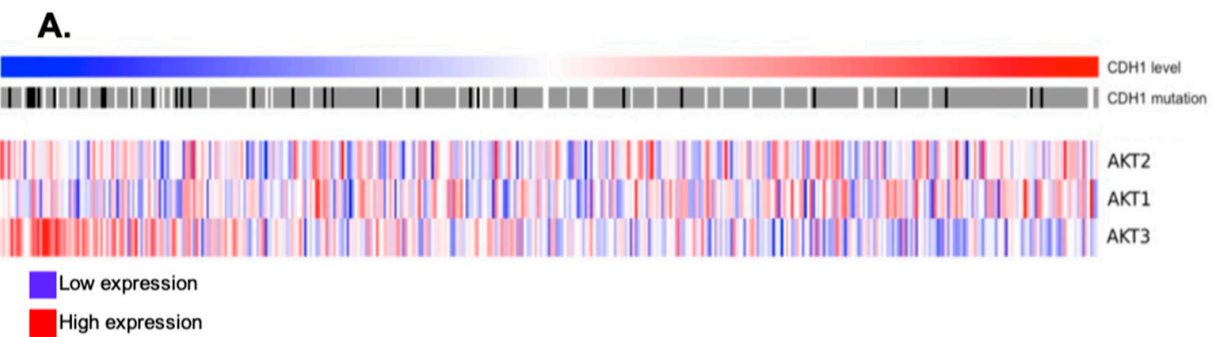

B.

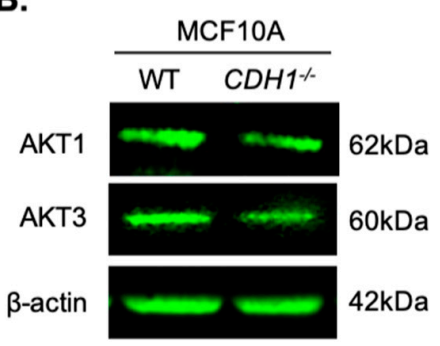

D.

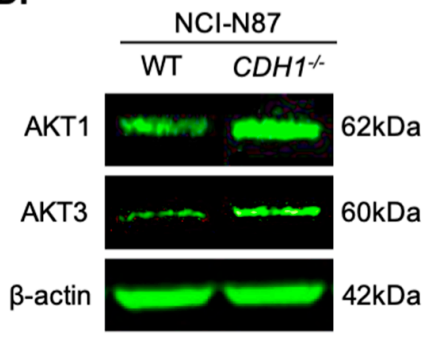

C.

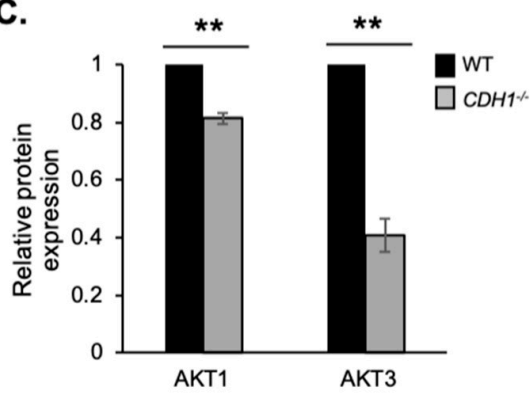

E.

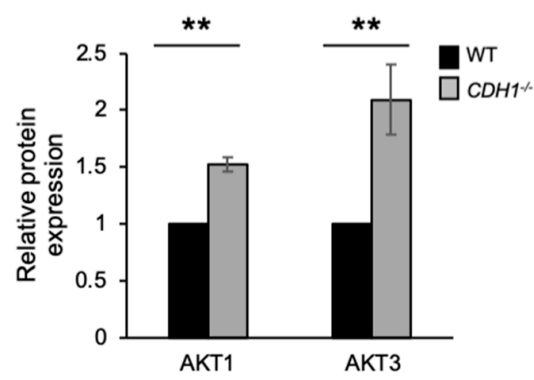

Figure 5. AKT isoforms are differentially regulated in CDH1-null gastric tumours, as well as non-malignant breast and gastric cancer cells. (A) Gene expression analysis of $A K T$ isoforms and $C D H 1$ in gastric cancer samples from the TCGA. Samples ordered by CDH1 expression level: Low to high (left to right). $C D H 1$ mutations: Light grey, wild-type; dark grey, silent somatic mutation; black, somatic mutation. (B) Protein expression of AKT1 and AKT3 in MCF10A-WT and MCF10A-CDH1 $1^{--}$ cells. (C) Relative expression of AKT1 and AKT3 protein in MCF10A-WT and MCF10A-CDH1 $1^{-1}$ cells. (D) Protein expression of AKT1 and AKT3 in NCI-N87-WT and NCI-N87-CDH1 ${ }^{-1-}$ cells. (E). Relative expression of AKT1 and AKT3 protein in NCI-N87-WT and NCI-N87-CDH1 ${ }^{-/}$cells. (For all graphs, error bars $=\mathrm{SEM} ;{ }^{* *}=p<0.01 ; n \geq 3$ independent biological replicates; unpaired two-sided $t$-test.) 


\section{Discussion}

In this study, we have demonstrated that breast and gastric cells lacking E-cadherin exhibit an enhanced sensitivity to cell death mediated by allosteric AKT inhibitors.

Importantly, there was a significant preferential priming of MCF10A-CDH1 ${ }^{-/}$cells for apoptosis after drug treatment, and this priming correlated well with the actual induction of apoptosis. Of the four allosteric AKT inhibitors tested, MK2206 and ARQ-092 exhibited the most consistent synthetic lethal relationship with E-cadherin in both breast and gastric cells. These drugs were selected to be tested in our novel gastric organoid model system - where both drugs preferentially inhibited the growth of organoids with $C d h 1$ conditional deletion compared with wild-type controls.

pAKT, pan-AKT, and isoforms 1 and 3 are downregulated in MCF10A cells lacking CDH1, but are upregulated in CDH1-deficient NCI-N87 cells. We hypothesise that in MCF10A-CDH1-/cells, their sensitivity to allosteric inhibitors is due to the very low levels of active AKT. It is well documented that AKT phosphorylation of the proapoptotic BAD protein [30] releases BAD binding of $\mathrm{Bcl}-\mathrm{xL}$ and prevents subsequent cytochrome $\mathrm{C}$ release from mitochondria, thereby inhibiting intrinsic apoptosis [31]. Decreased AKT expression in MCF10A-CDH1 ${ }^{-/-}$may be sensitising the cells to drug-induced apoptosis through this mechanism.

Conversely, we postulate that despite having significantly higher levels of AKT protein (pan, phospho, and AKT1 and 3), the NCI-N87-CDH1 ${ }^{-/-}$cells maintain sensitivity to allosteric inhibition of AKT because of an enhanced dependence on AKT signalling. Potentially, the upregulation of the pro-survival and pro-proliferative AKT signalling pathway may be a response to death signals being activated in these cells subsequent to the loss of $C D H 1$ expression and the acquisition of malignancy [32]. Loss of E-cadherin in cancer cells has been shown to activate AKT signalling as one mechanism to acquire resistance to anoikis subsequent to EMT [33,34].

Interestingly, the dual AKT-PDK1 allosteric inhibitor, PHT-427, exhibited no synthetic lethal effect in our MCF10A-CDH1 ${ }^{-/}$cells. While PDK1 is critical for the activation of AKT, via phosphorylation of Threonine 308 [35], it also acts as a "master kinase" with many documented targets [36]. The inhibition of PDK1 may have AKT-independent effects which interfere with the synthetic lethal effect of AKT inhibition alone.

AKT is postulated to contribute to gastric carcinogenesis and to influence prognosis [37], and our bioinformatic analysis of the TCGA dataset showed that there was significant upregulation of AKT3 RNA in CDH1-deficient tumours, but variable $A K T 1$ expression. Interestingly, in a recent proteomic study, upregulation of AKT pathways was found in CDH1-mutated diffuse gastric cancer tumours [13]. Therefore, AKT may represent an attractive drug target for gastric cancers with inactivating $\mathrm{CDH1}$ mutations.

Of the AKT inhibitors that have been developed for cancer treatment, the allosteric inhibitors used in this study are some of the most clinically advanced [38]. MK2206 has been shown in numerous studies to be well tolerated, but has exhibited limited efficacy as a monotherapy in a variety of solid tumours, such as gastric [39] and colorectal [40] cancers. However, trials of MK2206 in combination with traditional chemotherapeutic agents, such as paclitaxel, have had more success [41]. Additionally, MK2206 appears to synergise with EGFR/HER2 inhibition, and preliminary anti-tumour activity of MK2206 in combination with trastuzumab [42] has been documented. This leads to the possibility that MK2206 could be used in combination with other drugs to target diffuse gastric cancers with CDH1 mutations.

ARQ-092 has been shown to exhibit anti-tumour activity in a variety of solid and haematological tumours harbouring activating PIK3CA mutations [43], and promising clinical activity in patients harbouring $\mathrm{AKT}^{\mathrm{E} 17 \mathrm{~K}}$ mutations [44]. Encouraging anti-cancer activity was also demonstrated after ARQ-092 treatment in ovarian cancer patients previously treated with carboplatin and paclitaxel [45]. ARQ-092 is additionally being investigated for the primary treatment of Proteus syndrome, an overgrowth disorder resulting from an activating mutation in $A K T 1$ (AKT ${ }^{\mathrm{G} 49 \mathrm{~A}}$ ) [46]. Interestingly, the goals of the treatment of disorders such as Proteus syndrome would potentially align with our 
criteria for a chemopreventative strategy for patients lacking CDH1. Minimal toxicity is essential if ARQ-092 is to be used long-term. The first study to clinically evaluate tolerated ARQ-092 dose in adults and children with Proteus syndrome has just been published [47]. In general, the drug was well tolerated, with mostly grade 1 and 2 adverse effects. Importantly, ARQ-092 reduced phosphorylated AKT in affected tissues of most of the patients, as well as induced an apparent arrest of the cerebriform connective tissue nevus (CCTN) lesions present in the patients.

In conclusion, our study has demonstrated that cell lines (MCF10A and NCI-N87) and mouse-derived gastric organoids lacking $C D H 1$ are more sensitive to the apoptotic effects of allosteric AKT inhibitors. Bioinformatics analysis indicates that there is a strong correlation between the loss of $C D H 1$ and an increased expression of $A K T 3$ in gastric cancer. This has revealed a vulnerability in diffuse gastric cancer to AKT inhibition and we propose that this will lead to new chemoprevention and chemotherapy strategies for hereditary and sporadic diffuse gastric and lobular breast cancer patients.

\section{Materials and Methods}

\subsection{Cell Culture}

MCF10A cells (CRL 10317), a non-tumorigenic mammary epithelial cell line, and the derived isogenic line with CDH1 knockout (MCF10A-CDH1-/-) were purchased from Sigma (\#CLLS1042). The MCF10A isogenic lines were cultured in DMEM/F12: (1:1) (Invitrogen, Carlsbad, CA, USA) with $5 \%$ horse serum (Invitrogen), $10 \mu \mathrm{g} / \mathrm{mL}$ Actrapid neutral insulin (Novo Nordisk Pharmaceuticals Ltd. Bagsværd, Denmark), $20 \mathrm{ng} / \mathrm{mL}$ human epidermal growth factor (Peprotech, Rehovot, Israel), $100 \mathrm{ng} / \mathrm{mL}$ cholera toxin, and $500 \mathrm{ng} / \mathrm{mL}$ hydrocortisone (Sigma Aldrich, St Louis, MO, USA). NCI-N87 gastric cancer cells (CRL-5822) were purchased from ATCC and CDH1 knockouts were generated via Crispr-Cas9 (manuscript in preparation). Briefly, the NCI-N87-CDH1 ${ }^{-/}$cell line was generated using the following CRISPR guide RNA sequence: 5' GCTTCATTCACATCCAGCACATCCACGGTGAC 3' which targeted exon 10 of the $C D H 1$ gene. This gave rise to a single nucleotide frameshift deletion followed by a T/A SNP in the CDH1 gene, which was confirmed by Sanger sequencing. The NCI-N87 isogenic lines were cultured in DMEM/F12 (1:1) (Invitrogen) with 10\% fetal bovine serum (Invitrogen). All cells were grown at $37^{\circ} \mathrm{C}$ with $5 \% \mathrm{CO}_{2}$.

\subsection{Small Molecule Inhibitors and Chemicals}

The AKT inhibitors ipatasertib (\#S2808), AZD5363 (\#S8091), MK2206 (\#S1078), SC66 (\#S5313), and the BH3 mimetic ABT-737 (\#S1002) were purchased from SelleckChem (Houston, TX, USA). ARQ-092 (\#21388), perifosine (\#1008112), PHT-427 (\#24188), staurosporine (\#81590), digitonin (\#14952), and FCCP (\#15218) were purchased from Cayman Chemical. Oligomycin (\#O4876), $\beta$-mercaptoethanol (\#M3148), and endoxifen (E8285) were purchased from Sigma Aldrich (St Louis, MO, USA).

\subsection{Nuclei Enumeration Assay}

MCF10A-WT/MCF10A-CDH1 ${ }^{-/-}$and NCI-N87/NCI-N87-CDH1 ${ }^{-/-}$cells were seeded in 96-well black plates (Greiner, Kremsmünster, Austria) at 4 (MCF10A) or 10 (NCI-N87) $\times 10^{4}$ cells per well and left to attach overnight. The next day, outer wells of plates were stained with $1 \mu \mathrm{g} / \mathrm{mL}$ Hoechst 33,342 in PBS for $30 \mathrm{~min}$ and imaged on a Cytation 5 imager (Biotek, Winooski, VT, USA). Nuclei were counted at this stage to ensure plating accuracy. If the ratio of WT:CDH1 ${ }^{-/-}$cells was $>0.65$ and $<1.3$, then plates proceeded to drugging. Cells were drugged with a dose response of compounds as previously described [48] and incubated for a further $48 \mathrm{~h}$, cells were then fixed and stained with $1 \mu \mathrm{g} / \mathrm{mL}$ Hoechst 33,342, 0.25\% paraformaldehyde and 0.075\% saponin in PBS. Six fields/well at $4 \times$ magnification were captured using the Cytation 5 imager (Biotek). Nuclei were counted using Gen5 software (Biotek) and normalised to the vehicle control for each cell line. 


\subsection{Western Blotting}

MCF10A-WT and $\mathrm{CDH1}^{-/-}$cells ( 4 and $5 \times 10^{5}$ cells/plate) or NCI-N87-WT and $\mathrm{CDH1} 1^{-/-}$( 1 and $1.3 \times 10^{6}$ cells per plate) cells were seeded in $10 \mathrm{~cm}$ plates and left to attach overnight. Next, cells were left untreated or exposed to DMSO or drug treatment for $4 \mathrm{~h}$ in the incubator. Following drug treatment, plates were washed twice with ice cold TBS and stored at $-80^{\circ} \mathrm{C}$ for $\geq 1 \mathrm{~h}$. Cells were then scraped into $120 \mu \mathrm{L}$ of lysis buffer (25 mM HEPES, $100 \mathrm{mM} \mathrm{NaCl}, 1 \mathrm{mM}$ EDTA, $10 \%(v / v)$ glycerol, $1 \%$ $(v / v)$ Triton-X-100) containing Complete Mini Protease Inhibitor tablets (Roche, Basel, Switzerland). Tubes containing cell lysates were held on ice for $30 \mathrm{~min}$, vortexing every $5 \mathrm{~min}$, and then spun at $14,000 \mathrm{rpm}$ for $5 \mathrm{~min}$ at $4{ }^{\circ} \mathrm{C}$. The supernatant was moved to a clean tube and the protein concentration measured by BCA Assay (Thermo Fisher Scientific, Waltham, MA, USA). Next, $20 \mu \mathrm{g}$ of protein was mixed with 2X Laemmli buffer and run on 12\% SDS-Page gels. After transferring to nitrocellulose membranes, they were blocked with 5\%-BSA or milk in TBS-tween for $1 \mathrm{~h}$ and incubated overnight with primary antibodies at $4{ }^{\circ} \mathrm{C}$. Antibody concentrations: p-AKT Ser473 (Cell Signalling \#4060) at 1:1000, pan-AKT at 1:1000 (Cell Signalling \#2920), AKT1 at 1:1000 (Cell signalling \#75692), AKT3 at 1:1000 (Cell Signalling \#14982), E-cadherin 1:1000 (RnD Systems \#AF748), and B-actin 1:2500 (Sigma Aldrich \#A2066). Fluorescent secondary antibodies anti-rabbit (LI-COR \#925-32211), anti-goat (LI-COR \#925-32214), and anti-mouse (LI-COR \#925-32210) were used at 1:15,000. Membranes were imaged on LI-COR Odyssey Imaging System (Lincoln, NE, USA).

\subsection{FACS}

MCF10A and MCF10A-CDH1 ${ }^{-/-}$cells were seeded at 4 and $5 \times 10^{4}$ cells per well in 6-well plates. The next day, cells were drugged with AKT inhibitors and left for $72 \mathrm{~h}$. The day before analysis, control wells were drugged with Staurosporine $(0.1 \mu \mathrm{M})$. On the day of analysis, cells were trypsinised, spun down at $1500 \mathrm{rpm}$ for $5 \mathrm{~min}$, and resuspended in $500 \mu \mathrm{L}$ Annexin-binding buffer (10 mM Hepes ( $\mathrm{pH}$ 7.4), $140 \mathrm{mM} \mathrm{NaCl}, 2.5 \mathrm{mM} \mathrm{CaCl}_{2}$ ). Cells were stained with propidium iodide (Sigma Aldrich, St. Louis, MO, USA) and FITC-Annexin-V (\#556420, BD Biosciences, San Jose, CA, USA) for 15 min in the dark. Samples were analysed on BD Fortessa Flow cytometer. Compensation controls were: Untreated unstained, heat-treated cells stained with PI, and Staurosporine $(0.1 \mu \mathrm{M})$-treated cells stained with FITC-Annexin-V.

\subsection{Apoptosis Priming}

Our protocol for measuring apoptosis priming was based upon that described in Montero et al. [49]. MCF10A-WT and MCF10A-CDH1-/- cells were seeded at 1.5 and $1.8 \times 10^{5}$ cells per well in 6-well plates and left to attach overnight. The cells were then drugged with AKT inhibitors AZD5363 $(10 \mu \mathrm{M})$, ARQ-092 $(2 \mu \mathrm{M})$, MK2206 $(6.25 \mu \mathrm{M})$, perifosine $(7.5 \mu \mathrm{M})$, SC66 $(0.78 \mu \mathrm{M})$, the PI103 inhibitor PI103 $(1 \mu \mathrm{M})$, or the BH3 mimetic drug ABT-737 $(10 \mu \mathrm{M})$. DMSO $(0.1 \%)$ was used as a vehicle control. Following 16-20 h treatment, cells were trypsinised, counted, and washed with M-EB buffer $(150 \mathrm{mM}$ Mannitol, 10 mM HEPES-KOH pH 7.7, 50 mM KCl, 0.02 mM EGTA, 0.02 mM EDTA, 0.1\% BSA, 5 mM succinate). Cells were then stained with a $4 \times$ concentrated staining solution containing $4 \mathrm{mM} \mathrm{JC}-1$, $40 \mathrm{mg} / \mathrm{mL}$ oligomycin, $0.02 \%$ digitonin, $20 \mathrm{mM}$ 2-mercaptoethanol in M-EB. This cell/dye solution was left to stand at room temperature for $10 \mathrm{~min}$ in the dark to allow permeabilisation and dye equilibration. After staining, $15 \mu \mathrm{L}$ (containing 15,000 cells) was deposited per well in a black 384-well plate (Greiner, Kremsmünster, Austria) already containing $2 \times$ concentrated solutions of BIM BH3 peptide $(0.6 \mu \mathrm{M}$, purchased from New England Peptide) or FCCP $(12.5 \mu \mathrm{M})$ in ME-B. The plate was briefly shaken and equilibrated to $30{ }^{\circ} \mathrm{C}$ inside the CLARIOstar microplate reader (BMG Labtech, Ortenberg, Germany) and fluorescence at $590 \mathrm{~nm}$ monitored every $5 \mathrm{~min}$ for $65 \mathrm{~min}$. Percentage loss of mitochondrial membrane polarisation after drug treatment and exposure to BIM peptide was calculated by normalisation to the solvent only control DMSO ( $\%$ depolarisation) and the positive 
control FCCP (100\% depolarisation). Firstly, area under the curve (AUC) for each condition was calculated, followed by calculation of the depolarisation using the equation:

$$
\text { Depolarisation }=1\left(\mathrm{AUC}_{\text {sample }}-\mathrm{AUC}_{\mathrm{FCCP}}\right) /\left(\mathrm{AUC} \mathrm{DMSO}_{\mathrm{BUC}}-\mathrm{AUCP}_{\mathrm{FC}}\right)
$$

Individual depolarisation analysis was performed using 3-5 technical replicates for each control and sample.

\subsection{Organoid Culture}

Organoids were generated using the stomachs of neonatal mice and an inducible Cre-lox system [50], controlling both Cdh1 deletion and the activation of the fluorescent marker protein TdTomato under the CD44 stem cell promotor (CD44-Cre/Cdh1 $\left.\left({ }^{\mathrm{fl} / \mathrm{fl}}\right) / \mathrm{TdTomato}\right)$. Single loxP sites flank a region encompassing exons 6 through 10 of Cdh1, followed by a floxed selection cassette which was excised via in vitro Cre mediated recombination. Mice were used 1-2 days post-birth. Stomach tissue was removed and washed thoroughly in PBS with gentamycin before being minced to $<0.5 \mathrm{~mm}^{3}$ segments. Organoids were cultured in an air-liquid interface (ALI) system with myofibroblast co-culture (protocol adapted from [51]). Briefly, two separate $1.2 \mathrm{~mL}$ layers of collagen (Novachem, Calgary, AB, Canada) matrix were prepared inside a transwell insert (Corning, Corning, NY, USA), with both layers containing $5 \times 10^{5}$ myofibroblasts, and the top layer containing stomach tissue fragments. This transwell insert was placed inside a $35 \mathrm{~mm}$ dish, with $3 \mathrm{~mL}$ of growth medium added to the external dish. Organoid growth medium comprised F-12, 20\% FBS, and $50 \mu \mathrm{g} / \mathrm{mL}$ Gentamycin. Organoids were grown at $37^{\circ} \mathrm{C}$ with $5 \% \mathrm{CO}_{2}$. Knockout of $\mathrm{Cdh1}$ was induced by addition of endoxifen ( $5 \mu \mathrm{M}$ in DMSO) to the medium on day 0 post-seeding. An equivalent volume of DMSO was used for control wells. Growth of organoids was monitored daily by brightfield microscopy (Eclipse Ti Inverted Microscope System, Nikon, Tokyo, Japan).

\subsection{Drug Treatment of Organoids}

For each drug screen, organoids were established as described above. After $48 \mathrm{~h}$ in organoid growth medium containing endoxifen or DMSO, medium was replaced with media containing drug and/or DMSO. Brightfield images of the organoids were captured every $24 \mathrm{~h}$ (after plating) until $96 \mathrm{~h}$ (day 6) to monitor organoids. Images of individual organoids were assessed for changes in morphology and size, measured as area. Percentage area change per organoid from day 2 to day 6 was calculated. Significance was assessed by Wilcoxon rank sum test.

\subsection{RNA-seq Data}

The correlation analysis between $A K T$ (isoforms 1, 2, and 3) and CDH1 expression levels was assessed using RNA-seq data from the Stomach Adenocarcinoma (STAD) cohort in The Cancer Genome Atlas. Gene-level count data were downloaded from the International Cancer Genome Consortium data portal (https://dcc.icgc.org/releases/release_25) for 415 tumour samples, and normalised using the voom [52] methodology in the limma package for R [53]. The heatmap of AKT expression levels was generated using the gplots [54] package for $\mathrm{R}$ (version 3.4).

\section{Conclusions}

We have identified that breast cells, gastric cancer cells, and mouse-derived organoids that are E-cadherin-deficient have increased sensitivity to the allosteric AKT inhibitors ARQ-092 and MK2206. The identification of this synthetic lethal relationship may lead to new treatment strategies for hereditary and sporadic cancers with mutations in the $C D H 1$ gene.

Supplementary Materials: The following are available online at http:/www.mdpi.com/2072-6694/11/9/1359/ s1: Supplementary method: Immunofluorescence of organoids; Figure S1: E-cadherin is not expressed in MCF10A-CDH1 $1^{-/-}$or NCI-N87-CDH1 ${ }^{-/}$cells; Figure S2: Allosteric AKT inhibitors preferentially induce apoptosis 
in CDH1-null breast cells; Figure S3: E-cadherin expression in wild-type organoids; Figure S4: Assessment of percentage of Cdh1-null cells in a sample of organoids.

Author Contributions: Conceptualisation, N.B.-Z. and P.G.; methodology, N.B.-Z., Y.N., T.G., E.P., A.C., and M.A.B.; software, E.P. and M.A.B.; validation, Y.N., T.G., M.T., C.H., A.S., and T.B.; formal analysis, N.B.-Z., E.P., and M.A.B.; investigation, N.B.-Z., Y.N., M.T., C.H., and A.S.; resources, P.G.; data curation, E.P. and M.A.B.; writing - original draft preparation, N.B.Z. and P.G.; writing—review and editing, N.B.-Z., Y.N., T.G., M.T., C.H., A.S., T.B., E.P., A.C., M.A.B., and P.G.; visualisation, N.B.-Z.; supervision, P.G.; project administration, N.B.-Z. and P.G.; funding acquisition, P.G.

Funding: This work was supported by the Health Research Council (HRC) of New Zealand (grant number 17/16).

Conflicts of Interest: The authors declare no conflicts of interest.

\section{References}

1. Van Roy, F.; Berx, G. The cell-cell adhesion molecule E-cadherin. Cell. Mol. Life Sci. 2008, 65, 3756-3788. [CrossRef] [PubMed]

2. Wong, S.H.M.; Fang, C.M.; Chuah, L.-H.; Leong, C.O.; Ngai, S.C. E-cadherin: Its dysregulation in carcinogenesis and clinical implications. Crit. Rev. Oncol. Hematol. 2018, 121, 11-22. [CrossRef] [PubMed]

3. Guilford, P.J.; Hopkins, J.B.; Grady, W.M.; Markowitz, S.D.; Willis, J.; Lynch, H.; Rajput, A.; Wiesner, G.L.; Lindor, N.M.; Burgart, L.J.; et al. E-cadherin germline mutations define an inherited cancer syndrome dominated by diffuse gastric cancer. Hum. Mutat. 1999, 14, 249-255. [CrossRef]

4. van der Post, R.S.; Vogelaar, I.P.; Carneiro, F.; Guilford, P.; Huntsman, D.; Hoogerbrugge, N.; Caldas, C.; Schreiber, K.E.C.; Hardwick, R.H.; Ausems, M.G.E.M.; et al. Hereditary diffuse gastric cancer: Updated clinical guidelines with an emphasis on germline CDH1 mutation carriers. J. Med. Genet. 2015, 52, 361-374. [CrossRef] [PubMed]

5. Hansford, S.; Kaurah, P.; Li-Chang, H.; Woo, M.; Senz, J.; Pinheiro, H.; Schrader, K.A.; Schaeffer, D.F.; Shumansky, K.; Zogopoulos, G.; et al. Hereditary Diffuse Gastric Cancer Syndrome: CDH1 Mutations and Beyond. JAMA Oncol. 2015, 1, 23-32. [CrossRef] [PubMed]

6. Van der Post, R.S.; Oliveira, C.; Guilford, P.; Carneiro, F. Hereditary gastric cancer: what's new? Update 2013-2018. Fam. Cancer 2019, 15, 1-5. [CrossRef] [PubMed]

7. Pattison, S.; Mitchell, C.; Lade, S.; Leong, T.; Busuttil, R.A.; Boussioutas, A. Early relapses after adjuvant chemotherapy suggests primary chemoresistance in diffuse gastric cancer. PLoS ONE 2017, 12, e0183891. [CrossRef] [PubMed]

8. Telford, B.J.; Chen, A.; Beetham, H.; Frick, J.; Brew, T.P.; Gould, C.M.; Single, A.; Godwin, T.; Simpson, K.J.; Guilford, P. Synthetic Lethal Screens Identify Vulnerabilities in GPCR Signaling and Cytoskeletal Organization in E-Cadherin-Deficient Cells. Mol. Cancer Ther. 2015, 14, 1213-1223. [CrossRef]

9. Godwin, T.D.; Kelly, S.T.; Brew, T.P.; Bougen-Zhukov, N.M.; Single, A.B.; Chen, A.; Stylianou, C.E.; Harris, L.D.; Currie, S.K.; Telford, B.J.; et al. E-cadherin-deficient cells have synthetic lethal vulnerabilities in plasma membrane organisation, dynamics and function. Gastric Cancer 2018, 22, 273-286. [CrossRef]

10. Canaani, D. Methodological approaches in application of synthetic lethality screening towards anticancer therapy. Br. J. Cancer 2009, 100, 1213-1218. [CrossRef]

11. Pece, S.; Chiariello, M.; Murga, C.; Gutkind, J.S. Activation of the Protein Kinase Akt/PKB by the Formation of E-cadherin-mediated cell-cell junctions evidence for the association of phosphatidylinositol 3-kinase with the e-cadherin adhesion complex. J. Biol. Chem. 1999, 274, 19347-19351. [CrossRef] [PubMed]

12. Reddy, P.; Liu, L.; Ren, C.; Lindgren, P.; Boman, K.; Shen, Y.; Lundin, E.; Ottander, U.; Rytinki, M.; Liu, K. Formation of E-Cadherin-Mediated Cell-Cell Adhesion Activates Akt and Mitogen Activated Protein Kinase via Phosphatidylinositol 3 Kinase and Ligand-Independent Activation of Epidermal Growth Factor Receptor in Ovarian Cancer Cells. Mol. Endocrinol. 2005, 19, 2564-2578. [CrossRef] [PubMed]

13. Ge, S.; Xia, X.; Ding, C.; Zhen, B.; Zhou, Q.; Feng, J.; Yuan, J.; Chen, R.; Li, Y.; Ge, Z.; et al. A proteomic landscape of diffuse-type gastric cancer. Nat. Commun. 2018, 9, 1012. [CrossRef] [PubMed]

14. Chen, A.; Beetham, H.; Black, M.A.; Priya, R.; Telford, B.J.; Guest, J.; Wiggins, G.A.R.; Godwin, T.D.; Yap, A.S.; Guilford, P.J. E-cadherin loss alters cytoskeletal organization and adhesion in non-malignant breast cells but is insufficient to induce an epithelial-mesenchymal transition. BMC Cancer 2014, 14, 552. [CrossRef] [PubMed] 
15. Blake, J.F.; Xu, R.; Bencsik, J.R.; Xiao, D.; Kallan, N.C.; Schlachter, S.; Mitchell, I.S.; Spencer, K.L.; Banka, A.L.; Wallace, E.M.; et al. Discovery and preclinical pharmacology of a selective ATP-competitive Akt inhibitor (GDC-0068) for the treatment of human tumors. J. Med. Chem. 2012, 55, 8110-8127. [CrossRef] [PubMed]

16. Li, X.; Dai, D.; Chen, B.; Tang, H.; Xie, X.; Wei, W. Efficacy of PI3K/AKT/mTOR pathway inhibitors for the treatment of advanced solid cancers: A literature-based meta-analysis of 46 randomised control trials. PLoS ONE 2018, 13, e0192464. [CrossRef] [PubMed]

17. Nitulescu, G.M.; Margina, D.; Juzenas, P.; Peng, Q.; Olaru, O.T.; Saloustros, E.; Fenga, C.; Spandidos, D.A.; Libra, M.; Tsatsakis, A.M. Akt inhibitors in cancer treatment: The long journey from drug discovery to clinical use (Review). Int. J. Oncol. 2015, 48, 869-885. [CrossRef]

18. Chan, T.C.K.; Lapierre, J.-M.; Ashwell, M.A.; France, D.S.; Chen, C.-R.; Cornell-Kennon, S.; Bull, C.; Eathiraj, S.; Palma, R.; Liu, Y.; et al. Abstract A230: Discovery and characterization of ARQ 092, an ATP-independent, potent and selective inhibitor of AKT kinases. Mol. Cancer Ther. 2011, 10, A230.

19. Wu, W.-I.; Voegtli, W.C.; Sturgis, H.L.; Dizon, F.P.; Vigers, G.P.A.; Brandhuber, B.J. Crystal Structure of Human AKT1 with an Allosteric Inhibitor Reveals a New Mode of Kinase Inhibition. PLoS ONE 2010, 5, e12913. [CrossRef]

20. Poradosu, E.; Lemmon, M.; Keleti, D. Perifosine selectively inhibits binding of Akt PH domain to PtdIns( $(3,4) \mathrm{P} 2$. Cancer Res. 2007, 67, 1645.

21. Jo, H.; Lo, P.-K.; Li, Y.; Loison, F.; Green, S.; Wang, J.; Silberstein, L.E.; Ye, K.; Chen, H.; Luo, H.R. Deactivation of Akt by a small molecule inhibitor targeting pleckstrin homology domain and facilitating Akt ubiquitination. Proc. Natl. Acad. Sci. USA 2011, 108, 6486-6491. [CrossRef] [PubMed]

22. Meuillet, E.J. Novel Inhibitors of AKT: Assessment of a Different Approach Targeting the Pleckstrin Homology Domain. Curr. Med. Chem. 2011, 18, 2727-2742. [CrossRef] [PubMed]

23. Okuzumi, T.; Fiedler, D.; Zhang, C.; Gray, D.C.; Aizenstein, B.; Hoffman, R.; Shokat, K.M. Inhibitor hijacking of Akt activation. Nat. Chem. Biol. 2009, 5, 484-493. [CrossRef] [PubMed]

24. Meuillet, E.J.; Zuohe, S.; Lemos, R.; Ihle, N.; Kingston, J.; Watkins, R.; Moses, S.A.; Zhang, S.; Du-Cuny, L.; Herbst, R.; et al. Molecular pharmacology and antitumor activity of PHT-427, a novel Akt/phosphatidylinositide-dependent protein kinase 1 pleckstrin homology domain inhibitor. Mol. Cancer Ther. 2010, 9, 706-717. [CrossRef] [PubMed]

25. Lu, J.-W.; Lin, Y.-M.; Lai, Y.-L.; Chen, C.-Y.; Hu, C.-Y.; Tien, H.-F.; Ou, D.-L.; Lin, L.-I. MK-2206 induces apoptosis of AML cells and enhances the cytotoxicity of cytarabine. Med. Oncol. Northwood Lond. Engl. 2015, 32, 206. [CrossRef] [PubMed]

26. Cheng, Y.; Zhang, Y.; Zhang, L.; Ren, X.; Huber-Keener, K.J.; Liu, X.; Zhou, L.; Liao, J.; Keihack, H.; Yan, L.; et al. MK-2206, a Novel Allosteric Inhibitor of Akt, Synergizes with Gefitinib against Malignant Glioma via Modulating Both Autophagy and Apoptosis. Mol. Cancer Ther. 2012, 11, 154-164. [CrossRef]

27. Ryan, J.A.; Brunelle, J.K.; Letai, A. Heightened mitochondrial priming is the basis for apoptotic hypersensitivity of CD4+ CD8+ thymocytes. Proc. Natl. Acad. Sci. USA 2010, 107, 12895-12900. [CrossRef]

28. Ryan, J.; Letai, A. BH3 profiling in whole cells by fluorimeter or FACS. Methods 2013, 61, 156-164. [CrossRef]

29. Nagoshi, T.; Matsui, T.; Aoyama, T.; Leri, A.; Anversa, P.; Li, L.; Ogawa, W.; del Monte, F.; Gwathmey, J.K.; Grazette, L.; et al. PI3K rescues the detrimental effects of chronic Akt activation in the heart during ischemia/reperfusion injury. J. Clin. Investig. 2005, 115, 2128-2138. [CrossRef]

30. Datta, S.R.; Dudek, H.; Tao, X.; Masters, S.; Fu, H.; Gotoh, Y.; Greenberg, M.E. Akt phosphorylation of BAD couples survival signals to the cell-intrinsic death machinery. Cell 1997, 91, 231-241. [CrossRef]

31. Kennedy, S.G.; Kandel, E.S.; Cross, T.K.; Hay, N. Akt/Protein Kinase B Inhibits Cell Death by Preventing the Release of Cytochrome c from Mitochondria. Mol. Cell. Biol. 1999, 19, 5800-5810. [CrossRef] [PubMed]

32. Lu, M.; Marsters, S.; Ye, X.; Luis, E.; Gonzalez, L.; Ashkenazi, A. E-cadherin couples death receptors to the cytoskeleton to regulate apoptosis. Mol. Cell 2014, 54, 987-998. [CrossRef] [PubMed]

33. Chunhacha, P.; Sriuranpong, V.; Chanvorachote, P. Epithelial-mesenchymal transition mediates anoikis resistance and enhances invasion in pleural effusion-derived human lung cancer cells. Oncol. Lett. 2013, 5, 1043-1047. [CrossRef] [PubMed]

34. Cao, Z.; Livas, T.; Kyprianou, N. Anoikis and EMT: Lethal "Liaisons" during Cancer Progression. Crit. Rev. Oncog. 2016, 21, 155-168. [CrossRef] [PubMed] 
35. Stephens, L.; Anderson, K.; Stokoe, D.; Erdjument-Bromage, H.; Painter, G.F.; Holmes, A.B.; Gaffney, P.R.; Reese, C.B.; McCormick, F.; Tempst, P.; et al. Protein kinase B kinases that mediate phosphatidylinositol 3,4,5-trisphosphate-dependent activation of protein kinase B. Science 1998, 279, 710-714. [CrossRef] [PubMed]

36. Belham, C.; Wu, S.; Avruch, J. Intracellular signalling: PDK1-A kinase at the hub of things. Curr. Biol. 1999, 9, R93-R96. [CrossRef]

37. Cinti, C.; Vindigni, C.; Zamparelli, A.; La Sala, D.; Epistolato, M.C.; Marrelli, D.; Cevenini, G.; Tosi, P. Activated Akt as an indicator of prognosis in gastric cancer. Virchows Arch. Int. J. Pathol. 2008, 453, 449-455. [CrossRef] [PubMed]

38. Brown, J.S.; Banerji, U. Maximising the potential of AKT inhibitors as anti-cancer treatments. Pharmacol. Ther. 2017, 172, 101-115. [CrossRef]

39. Ramanathan, R.K.; McDonough, S.L.; Kennecke, H.F.; Iqbal, S.; Baranda, J.C.; Seery, T.E.; Lim, H.J.; Hezel, A.F.; Vaccaro, G.M.; Blanke, C.D. Phase 2 study of MK-2206, an allosteric inhibitor of AKT, as second-line therapy for advanced gastric and gastroesophageal junction cancer: A SWOG cooperative group trial (S1005). Cancer 2015, 121, 2193-2197. [CrossRef]

40. Dasari, A.; Overman, M.J.; Fogelman, D.R.; Kee, B.K.; Menter, D.; Raghav, K.P.S.; Morris, V.K.; Oh, J.; Wu, J.; Jiang, Z.; et al. A phase II and co-clinical study of an AKT inhibitor in patients (pts) with biomarker-enriched, previously treated metastatic colorectal cancer (mCRC). J. Clin. Oncol. 2016, 34, 3563. [CrossRef]

41. Gonzalez-Angulo, A.M.; Krop, I.; Akcakanat, A.; Chen, H.; Liu, S.; Li, Y.; Culotta, K.S.; Tarco, E.; Piha-Paul, S.; Moulder-Thompson, S.; et al. SU2C Phase Ib Study of Paclitaxel and MK-2206 in Advanced Solid Tumors and Metastatic Breast Cancer. JNCI J. Natl. Cancer Inst. 2015, 107, dju493. [CrossRef]

42. Hudis, C.; Swanton, C.; Janjigian, Y.Y.; Lee, R.; Sutherland, S.; Lehman, R.; Chandarlapaty, S.; Hamilton, N.; Gajria, D.; Knowles, J.; et al. A phase 1 study evaluating the combination of an allosteric AKT inhibitor (MK-2206) and trastuzumab in patients with HER2-positive solid tumors. Breast Cancer Res. 2013, 15, R110. [CrossRef] [PubMed]

43. Tolcher, A.; Harb, W.; Sachdev, J.; Papadopoulos, K.; Bordoni, R.; Chai, F.; Larmar, M.; Savage, R.; Abbadessa, G.; Saleh, M. 338 Results from a phase 1 study of ARQ 092, a novel pan AKT-inhibitor, in subjects with advanced solid tumors or recurrent malignant lymphoma. Eur. J. Cancer 2015, 51, S66. [CrossRef]

44. Abbadessa, G.; Yu, Y.; Eathiraj, S.; Meade, J.; Wick, M.J.; Tolcher, A.; Papadopoulos, K.; Saleh, M.; Sachdev, J.; Chai, F.; et al. Abstract B181: Association of AKT1E17K and PIK3CAH1047R mutations with efficacy of ARQ 092 in vitro, in vivo and in patients. Mol. Cancer Ther. 2015, 14, B181.

45. Lakhani, N.; Tolcher, A.W.; Rasco, D.W.; Patnaik, A.; O’Rourke, T.J.; Schwartz, B.E.; Abbadessa, G.; Kazakin, J.; Savage, R.; Wang, Y.; et al. Results of a phase Ib study of ARQ 092 in combination with carboplatin (C) plus paclitaxel (P), or with P in patients (pts) with solid tumors. J. Clin. Oncol. 2017, 35, 2524. [CrossRef]

46. Lindhurst, M.J.; Yourick, M.R.; Yu, Y.; Savage, R.E.; Ferrari, D.; Biesecker, L.G. Repression of AKT signaling by ARQ 092 in cells and tissues from patients with Proteus syndrome. Sci. Rep. 2015, 5, 17162. [CrossRef]

47. Keppler-Noreuil, K.M.; Sapp, J.C.; Lindhurst, M.J.; Darling, T.N.; Burton-Akright, J.; Bagheri, M.; Dombi, E.; Gruber, A.; Jarosinski, P.F.; Martin, S.; et al. Pharmacodynamic Study of Miransertib in Individuals with Proteus Syndrome. Am. J. Hum. Genet. 2019, 104, 484-491. [CrossRef]

48. Single, A.; Beetham, H.; Telford, B.J.; Guilford, P.; Chen, A. A Comparison of Real-Time and Endpoint Cell Viability Assays for Improved Synthetic Lethal Drug Validation. J. Biomol. Screen. 2015, 20, 1286-1293. [CrossRef]

49. Montero, J.; Sarosiek, K.A.; DeAngelo, J.D.; Maertens, O.; Ryan, J.; Ercan, D.; Piao, H.; Horowitz, N.S.; Berkowitz, R.S.; Matulonis, U.; et al. Drug-induced death signaling strategy rapidly predicts cancer response to chemotherapy. Cell 2015, 160, 977-989. [CrossRef]

50. Kühn, R.; Torres, R.M. Cre/loxP recombination system and gene targeting. Methods Mol. Biol. 2002, 180, 175-204.

51. Pastuła, A.; Middelhoff, M.; Brandtner, A.; Tobiasch, M.; Höhl, B.; Nuber, A.H.; Demir, I.E.; Neupert, S.; Kollmann, P.; Mazzuoli-Weber, G.; et al. Three-Dimensional Gastrointestinal Organoid Culture in Combination with Nerves or Fibroblasts: A Method to Characterize the Gastrointestinal Stem Cell Niche. Available online: https://www.hindawi.com/journals/sci/2016/3710836/ (accessed on 16 February 2019).

52. Law, C.W.; Chen, Y.; Shi, W.; Smyth, G.K. voom: Precision weights unlock linear model analysis tools for RNA-seq read counts. Genome Biol. 2014, 15, R29. [CrossRef] [PubMed] 
53. R Core Team. R: A Language and Environment for Statistical Computing; R Foundation for Statistical Computing: Vienna, Austria, 2019.

54. Warnes, G.R.; Bolker, B.; Bonebakker, L.; Gentleman, R.; Huber, W.; Liaw, A.; Lumley, T.; Maechler, M.; Magnusson, A.; Moeller, S.; et al. gplots: Various R Programming Tools for Plotting Data. R Package Version 3.0.1. 2016. Available online: https://rdrr.io/cran/gplots/ (accessed on 12 September 2019).

(C) 2019 by the authors. Licensee MDPI, Basel, Switzerland. This article is an open access article distributed under the terms and conditions of the Creative Commons Attribution (CC BY) license (http://creativecommons.org/licenses/by/4.0/). 